\title{
Exploring the Occurrence of Clogging in Highly Permeable Coarse Soils of Dam Foundations
}

\author{
Jianquan Ma $\mathbb{C D}^{1,2}$ Hao Peng, ${ }^{1}$ Shibo Li $\left(\mathbb{D},{ }^{1,2}\right.$ Zhao Duan, $^{1,2}$ Xinshe Zhang, ${ }^{3}$ and Donghe Ma ${ }^{4}$ \\ ${ }^{1}$ College of Geology and Environment, Xi'an University of Science and Technology, Xi'an 710054, China \\ ${ }^{2}$ Shaanxi Provincial Key Laboratory of Geological Support for Coal Green Exploitation, Xi'an 710054, China \\ ${ }^{3}$ Xi'an Center of Geological Survey, China Geological Survey, 710054 Xi'an, China \\ ${ }^{4}$ China Water Northeastern Investigation, Design \& Research Co., Ltd., Changchun 130021, China \\ Correspondence should be addressed to Shibo Li; lishibo@xust.edu.cn
}

Received 26 March 2020; Revised 10 June 2020; Accepted 16 June 2020; Published 25 July 2020

Academic Editor: Daniele Baraldi

Copyright ( $\odot 2020$ Jianquan Ma et al. This is an open access article distributed under the Creative Commons Attribution License, which permits unrestricted use, distribution, and reproduction in any medium, provided the original work is properly cited.

\begin{abstract}
Leakage through the permeable coarse soils of dam foundations in Tibet, China, lessened over time without any additional antiseepage measures. In fact, clogging generated during the infiltration process is recognized as the major factor in reducing leakage. A laboratory study was conducted to understand clogging in highly permeable coarse soil of a dam foundation with the primary aim of determining the clogging patterns and optimum clogging particle size (PS). Seven replicate experiments were constructed using soil media with PS ranges of $32-64 \mathrm{~mm}, 16-32 \mathrm{~mm}, 8-16 \mathrm{~mm}, 4-8 \mathrm{~mm}, 2-4 \mathrm{~mm}, 1-2 \mathrm{~mm}$, and $0.5-1 \mathrm{~mm}$ to observe clogging after feeding the soil media with sediments of different PSs. The experimental results showed that four clogging patterns were formed in different PSs of the coarse foundation soil. The ratio of the effective aperture of the soil $D_{\text {ea }}$ and the equivalent clogging particle size $d_{e}\left(d_{e} / D_{\text {ea }}\right)$ had a dominant effect on the four clogging patterns (surface clogging, $\left(d_{e} / D_{\text {ea }}\right)>1$; surface-internal clogging, $0.5<\left(d_{e} / D_{\text {ea }}\right) \leq 1$; internal partial pore blockage, $0.25<\left(d_{e} / D_{\text {ea }}\right) \leq 0.5$; and unclogging, $\left.\left(d_{e} / D_{\mathrm{ea}}\right) \leq 0.25\right)$. The assessment criterion of the optimum clogging pattern was determined by $0.5<\left(d_{e} / D_{\mathrm{ea}}\right) \leq 1$, and from that, the optimum clogging PS $d_{\mathrm{o}}$ was calculated.
\end{abstract}

\section{Introduction}

Leakage is a major safety issue that influences the economic value of dams and threatens dam stability [1-4]. It was reported that the sediments of the reservoir dam foundation in Shannan, located in the south of Tibet Province, China, were deep and overlain by coarse-grained soils originating from glacial deposits and characterized by physical weathering and high permeability $[5,6]$, creating a risk of leakage $[7,8]$. Due to continuing seepage and erosion of the dam's foundation, the flow rate in the soil foundation increased gradually. This increased the seepage through the dam foundation and caused concentrated erosion of the finegrained material at the soil interface with the dam foundation, finally leading to failure of the dam's foundation $[9,10]$. A decades-long survey of five reservoirs (Daranduo Reservoir, Jiangxiong Reservoir, Jiaripu Reservoir,
Qiongguo Reservoir, and Awoduo Reservoir, as shown in Figure 1(a)) in the Shannan area found that the state of leakage in the dam foundations at these sites lessened with time without any additional antiseepage measures [11-13]. The reason for this phenomenon was verified under seepage conditions in the dam foundation and was attributed to fine soil particles that were transported and retained in the pores, thus reducing leakage [6]. Therefore, placing fine sediments into foundation soil pores can serve as a recovery technology approach for leakage in foundation soil, similar to using geomembranes, as an effective method of clogging.

Sedimentation of fine particles can influence the permeability of soil [14], which has been verified in soil filters in geotechnical engineering. By preventing the erosion of base soils and building up pore pressure, clogging provided an effective method to obtain internal stability [9, 15]. It is evident from research in porous media that physical 

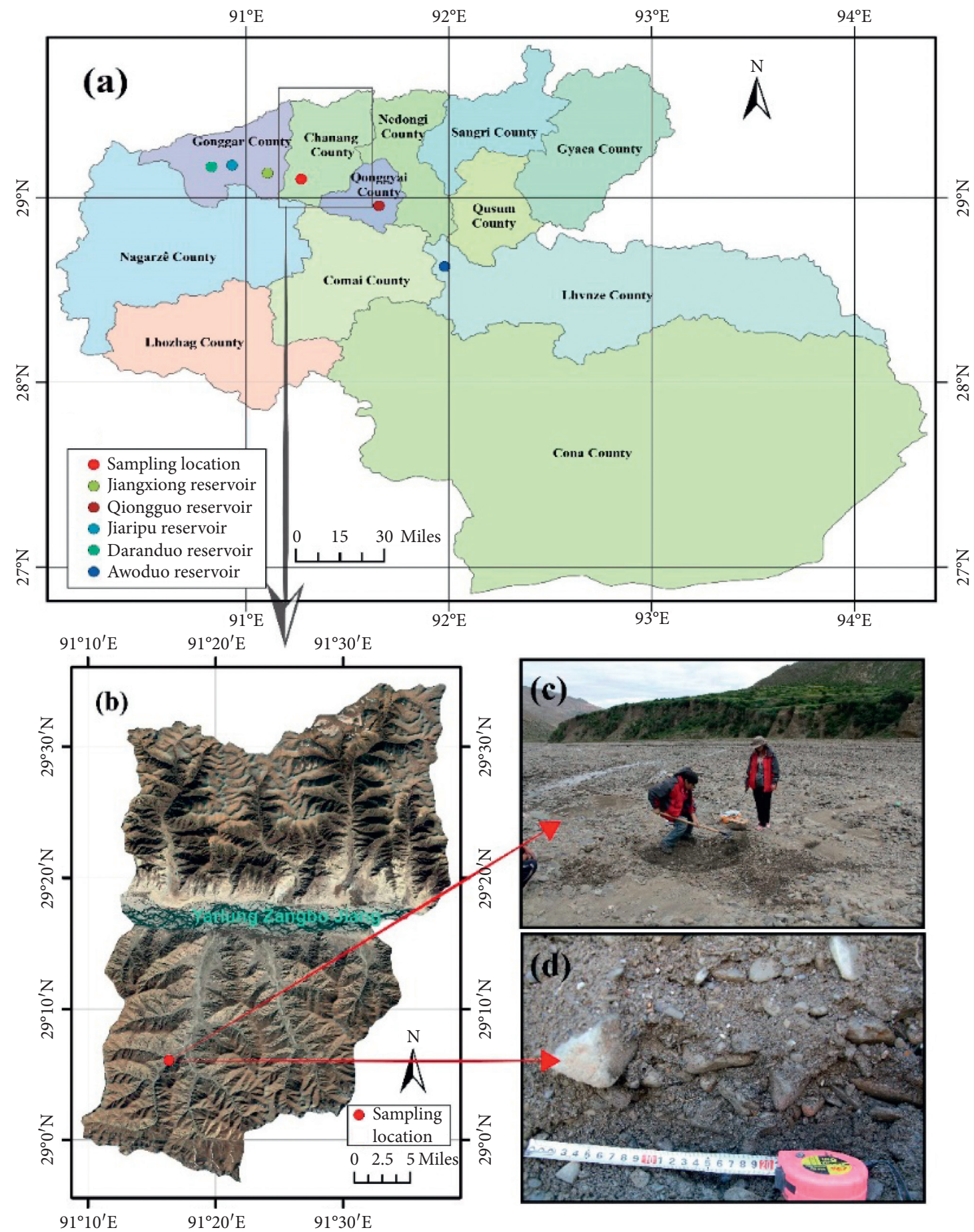

FIgURE 1: The study site, located on Shannan of Tibet, China. (a) Five typical water reservoirs with leakage in strong infiltrating coarse soil of dam foundation. (b) Location of sample selected and Yarlung Zangbo Jiang river system. (c) Location for sampling site. (d) Status of field soil sediments of the sample.

clogging may be more likely to occur under constant head conditions than under constant flow rates [16], similar to the highly permeable coarse soils of the dam foundations in Qiongguo reservoir and Jiangxiong reservoir [12]. The study on the permeability and mechanical properties of saturated cohesionless soil by laboratory tests shows that hydraulic gradient would drop and flow velocity would increase under long-term infiltration and large amounts of fine particles are eroded away, which finally caused the reduction of the soil strength at the major stage of drained shearing $[7,17]$.

In surveys of clogging events in the disciplines of environmental engineering, geotechnical engineering, and biological engineering, clogging particles were mostly fine particles, such as sandy-silt [18], suspended solids [19-22], 
clay [23], or even colloid deposits [24]. For filter media, particle size includes two types: fine media, such as sandy loam [25], fine sand [26, 27], compost, and peat [19]; and coarse media, such as sand or mulch soil $[20,21]$ and even gravel beds $[28,29]$. Unfortunately, highly permeable dam foundation media are always nonuniform and contain larger-sized particles, such as boulders, pebbles, or gravel deposits, which differ from the aforementioned filter media. In high constant head conditions, the clogging particles are always gravelly sands; silt, clay, or suspended solids could not clog or be trapped in the pores of the particles [12]. McIsaac and Rowe [30] have found that significant differences exist in permeability because of the difference in the media particle size and even found a hydraulic conductivity that was twice as high in a coarse gravel bed $(38 \mathrm{~mm})$ as in a $19 \mathrm{~mm}$ gravel. In particular, in coarse soil of spreading gradation as our study media, different particle size distributions will determine different suitable equivalent particle sizes, which affect clogging and permeability performance [31]. In addition, the hydraulic characteristics of soil media are very sensitive to the soil media particle size [32].

Schälchli [33] indicated that flow conditions, such as the hydraulic conductivity of the soil filter, the shape, and size of suspended particles, the hydraulic gradient of the seepage flow, and the concentrations of suspended solids, have a dominant influence on physical clogging. Both sediment grains and suspended particles can cause clogging. The evolution of hydraulic characteristics over time and a reduction in permeability are evidence of clogging [34, 35]. The experimental observation shows that the hydraulic gradient is the most influential parameter in the clogging of sands and gravels [36]. Therefore, this article focuses on the changes to hydraulic characteristics (hydraulic gradient and flow velocity) caused by clogging and the influence of particle size (both of clogging sediments and soil media) on clogging. We also focus on building a relationship in clogging behavior, filter media particle size, and incoming particle size. A series of laboratory physical clogging experiments were conducted for this study.

\section{Experimental Works}

2.1. Materials. The materials used in this study were natural materials similar to the real dam foundation media obtained upstream of Zhuo Yu Gou in the middle of the Qiongguo and Jiangxiong Reservoirs, Shannan, Tibet (Figure 1). The materials were divided into two parts, soil media (as skeleton particles in the experiments) and incoming sediments (the particles added in the column to checking clogging or not in the experiments). To assess the impact of particle size on clogging, the particle size distributions (PSDs) of all the materials are in accordance with the Udden-Wentworth scale $[37,38]$.

In the research of foundation leakage in Shannan, the dam foundation soil mainly included boulders, pebbles, gravel, and sand and contained cohesive soil, rounded but poorly sorted with particle sizes mainly larger than $0.5 \mathrm{~mm}$ $[5,39]$. In this study, the soil media particle size (PS) was sieved into $32-64 \mathrm{~mm}, 16-32 \mathrm{~mm}, 8-16 \mathrm{~mm}, 4-8 \mathrm{~mm}$,
2-4 mm, 1-2 mm, and $0.5-1 \mathrm{~mm}$ ranges. Similar to particle migration and erosion processes, these media cover a range of gravel and sand sizes [40]. The dry density and porosity of the soil media and the PSs of the incoming sediments are shown in Table 1. To obtain soils that were inert to each other, all soil particles were sieved by soaking in water.

2.2. Experimental Apparatus. For the purpose of the experimental works, a special infiltration-clogging monitoring system was built. The infiltration-clogging monitoring system comprised four parts: sample column, feeding column connected to a feeding pipe, monitoring equipment, and water supply tank with circulation function. Both the sample column and feeding column were $500 \mathrm{~mm}$ in height and $370 \mathrm{~mm}$ in diameter and made of Plexiglas (Figure 1). As recommended for seepage studies in coarse-particle soils [41], the ratio of the sample column diameter to the soil media particle diameter was more than 5 to 6 , appropriate for media particles smaller than $64 \mathrm{~mm}$. Hydraulic head distributions along the soil media were measured by pore water pressure sensors, which were connected to a computer and laterally buried to the sample column. To avoid a preferential flow path between the soil and the Plexiglas cell wall, the monitoring point of hydraulic head change was selected at the center of the sample.

From the feeding pipe, incoming sediments filled in, and the damping plates in the feeding column ensured even distribution of the incoming particles. Reddi et al. [42] and Alem et al. [16] indicated that clogging appeared to be greater under the condition of a constant head than under a constant flow rate. During the operation period, a submersible pump was used to continuously supply water to the constant head controller using a pressure tank and to circulate water in the water supply tank. In the experiment, a $6 \mathrm{~m}$ water head was provided by a pressure tank and was stabilized by the top sensor. Figure 2 shows a schematic and photograph of the system.

2.3. Experimental Procedure and Data Analysis. After placing the fully compacted soil media layer by layer, the sample column was checked for leakage before each test. To release air bubbles in the soil media, after one layer of soil media was fully saturated, another was placed. After the device was installed and after setting a constant hydraulic head, the experiment started. Before feeding sediment particles, the hydraulic head and flow velocity were first stabilized. Then, incoming sediments were slowly and uniformly fed into the apparatus. For soil media in the same PS, the same stable time was selected for feeding in each experiment. The clogging phenomenon was monitored by the flow velocity and hydraulic gradient. The hydraulic gradient was calculated by monitoring the hydraulic head, which is the rate of change in hydraulic head per unit of distance of flow.

A $6 \mathrm{~m}$ stable head height was set in the test. The hydraulic gradient for different soil media PSs should be approximately 12 for a specimen height of $0.5 \mathrm{~m}$. However, to ensure hydraulic head stability, the hydrovalve (Figure 2) was adjusted to change the flow velocity. Thus, the flow velocity 
TABLE 1: Basic properties of soil media and corresponding PSs of incoming sediment.

\begin{tabular}{|c|c|c|c|c|c|c|c|c|c|}
\hline \multirow{2}{*}{ Incoming PS (mm) } & \multirow{2}{*}{ Dry density $\left(\rho_{d} / \mathrm{g} / \mathrm{cm}^{3}\right)$} & \multirow{2}{*}{ Porosity $\left(n_{\mathrm{s}}\right)$} & \multicolumn{7}{|c|}{ Soil media PS (mm) } \\
\hline & & & $32-64$ & $16-32$ & $8-16$ & $4-8$ & $2-4$ & $1-2$ & $0.5-1$ \\
\hline $4-8$ & 1.63 & 0.326 & $T_{1}$ & $T_{8}$ & & & & & \\
\hline $2-4$ & 1.63 & 0.310 & $T_{2}$ & $T_{9}$ & $T_{15}$ & & & & \\
\hline $1-2$ & 1.65 & 0.290 & $T_{3}$ & $T_{10}$ & $T_{16}$ & $T_{21}$ & & & \\
\hline $0.5-1$ & 1.66 & 0.307 & $T_{4}$ & $T_{11}$ & $T_{17}$ & $T_{22}$ & $T_{26}$ & & \\
\hline $0.25-0.5$ & 1.69 & 0.347 & $T_{5}$ & $T_{12}$ & $T_{18}$ & $T_{23}$ & $T_{27}$ & $T_{30}$ & \\
\hline $0.125-0.25$ & 1.73 & 0.332 & $T_{6}$ & $T_{13}$ & $T_{19}$ & $T_{24}$ & $T_{28}$ & $T_{31}$ & $T_{33}$ \\
\hline $0.063-0.125$ & 1.79 & 0.341 & $T_{7}$ & $T_{14}$ & $T_{20}$ & $T_{25}$ & $T_{29}$ & $T_{32}$ & $T_{34}$ \\
\hline
\end{tabular}

Note. $T_{\mathrm{i}}$ denotes the experiments' serial number of different incoming sediments in different soil media PSs.

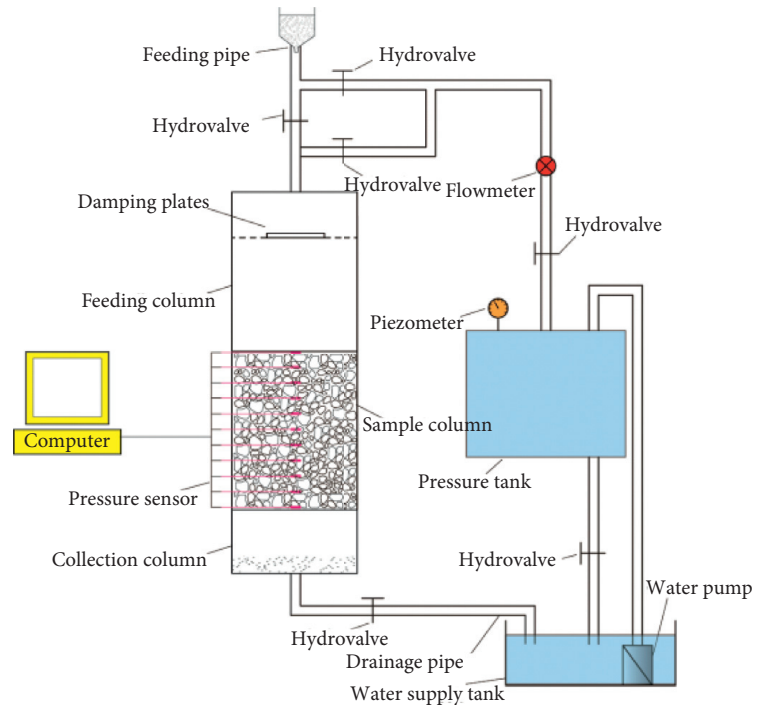

(a)

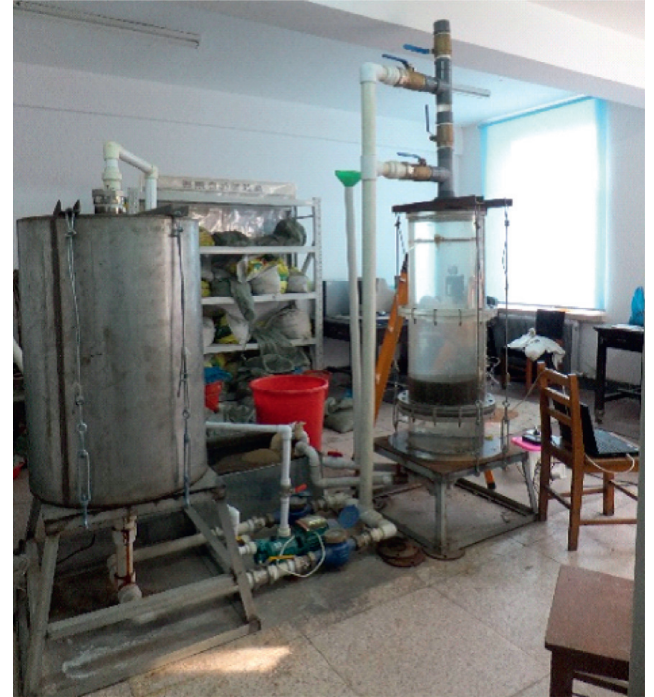

(b)

Figure 2: Infiltration-clogging monitor system. (a) Schematic diagram. (b) Photograph.

varied with time and was different than the hydraulic gradient for the 34 experiments. However, for the flow velocity obtained in the 34 experiments, Darcy's law does not apply. The hydraulic conductivity was not selected to illustrate the results, and instead, a discussion of the experimental hydraulic characteristics based on the hydraulic gradient and flow velocity is provided.

After feeding the particles for a period of time, the monitoring data reach the secondary stable state, and the experiment was deemed finished. The lost particles under the drainage pipe were collected, and the soil media in the sample column were layered and sieved after the experiment.

\section{Results and Discussion}

\subsection{Laboratory Experiment Results}

3.1.1. Hydraulic Characteristics. According to Figure 3, it can be seen that the hydraulic gradient remained relatively constant at first (approximately 12) and increased significantly with time after some particle sizes were introduced before it dropped with time and finally became stable at the initial value (approximately 12).
Under the same hydraulic head and for a fixed sample column, clogging in a smaller PS of the soil media resulted in a higher increase in the amplitude of the hydraulic gradient. Moreover, for the same PS of the soil media, the increased amplitude of the hydraulic gradient was different after introducing different sizes of incoming particles. For instance, the hydraulic gradient increased to its highest point after incoming PSs of $0.063-0.125 \mathrm{~mm}$ were introduced following soil media particles sizes of $0.5-1 \mathrm{~mm}$, as shown in Figure $3(\mathrm{~g})$, and the same was observed for soil media PSs of $1-2 \mathrm{~mm}$ following incoming PSs of $0.125-0.25 \mathrm{~mm}$ in Figure 3(f), soil media PSs of 2-4 mm following incoming PSs of $0.25-0.5 \mathrm{~mm}$ in Figure 3(e), soil media PSs of $4-8 \mathrm{~mm}$ following incoming PSs of $0.5-1 \mathrm{~mm}$ in Figure $3(\mathrm{~d})$, soil media PSs of 8-16 mm following incoming PSs of $1-2 \mathrm{~mm}$ in Figure 3(c), soil media PSs of 16-32 mm following incoming PSs of $2-4 \mathrm{~mm}$ in Figure $3(\mathrm{~b})$, and soil media PSs of 32-64 mm following incoming PSs of $4-8 \mathrm{~mm}$ in Figure 3(a), respectively.

In addition to the above variation, the hydraulic gradient curve shows exhibited fluctuations. This does not necessarily represent variations in the hydraulic gradient because when the water pump feeds the water circulated from the column, 

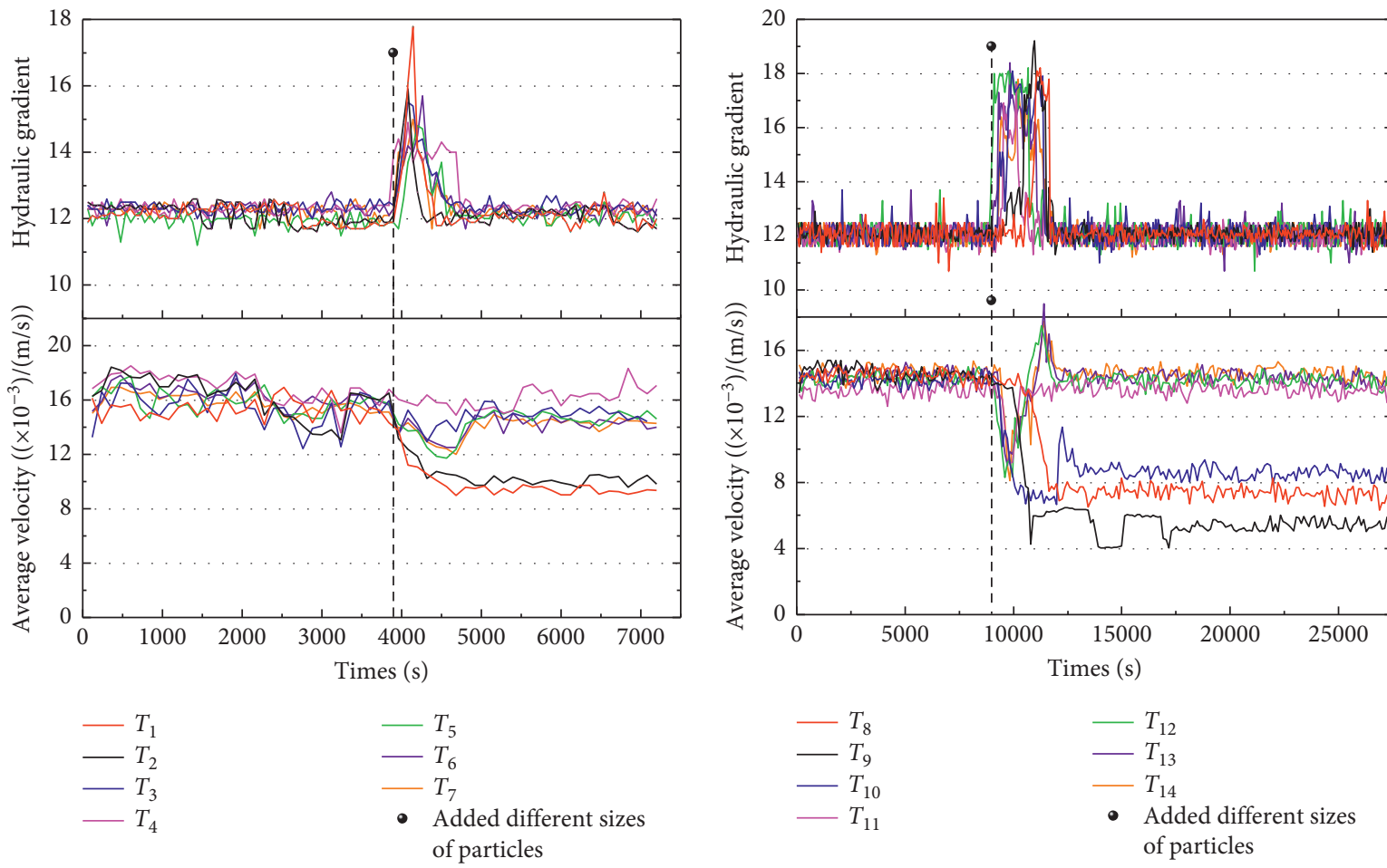

(a)
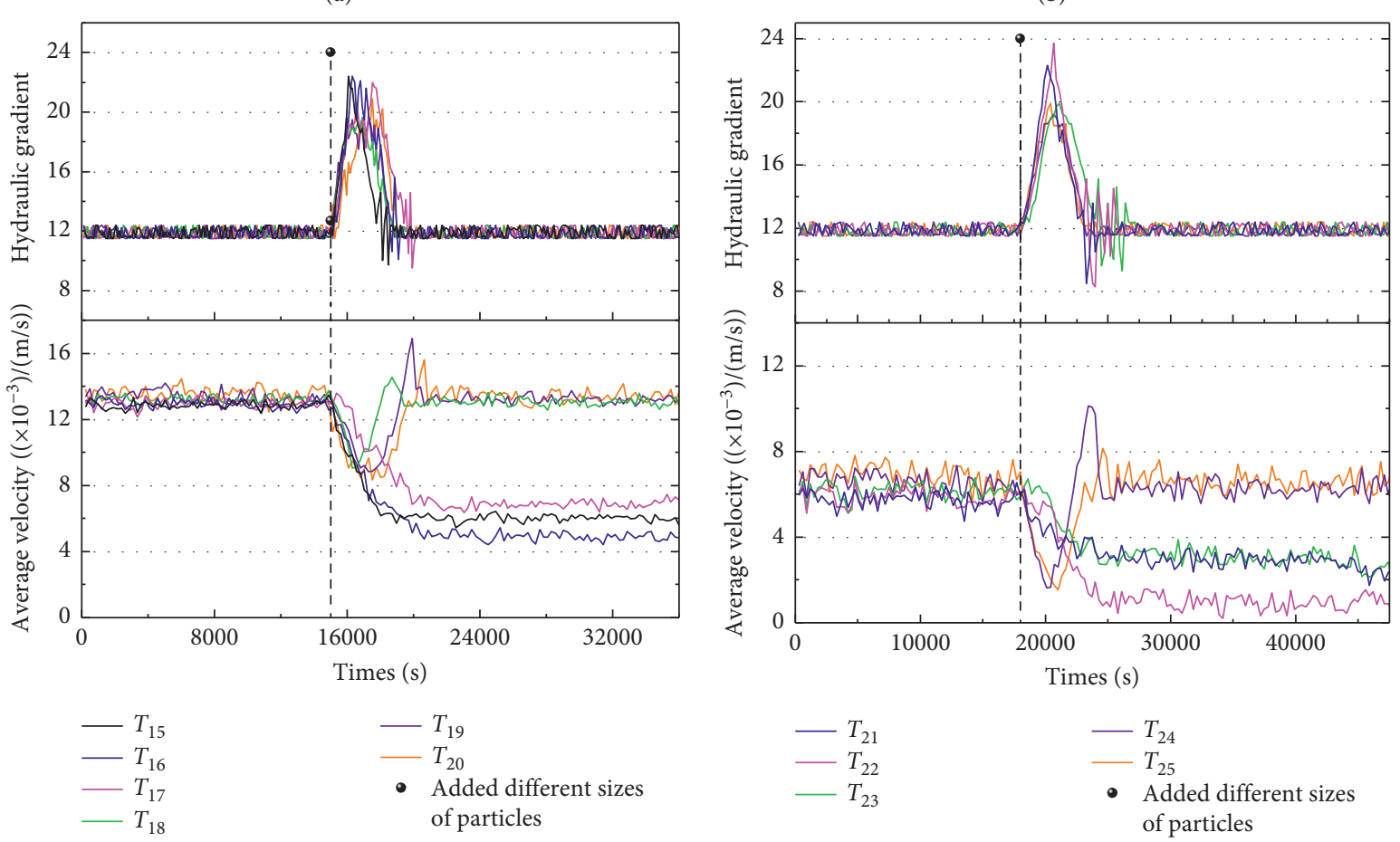

$$
\begin{array}{r}
T_{15} \\
-T_{16} \\
-T_{17}
\end{array}
$$$$
-T_{5}
$$$$
-T_{6}
$$$$
\text { - Added different sizes }
$$
of particles

(b)

(c)

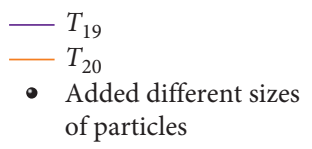

(d)

Figure 3: Continued. 


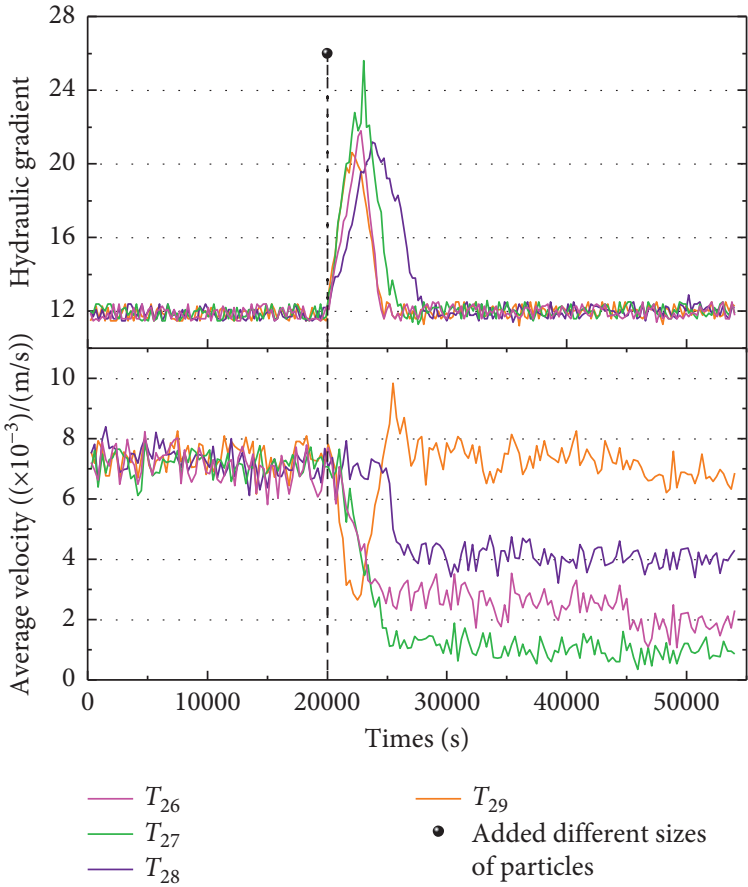

(e)

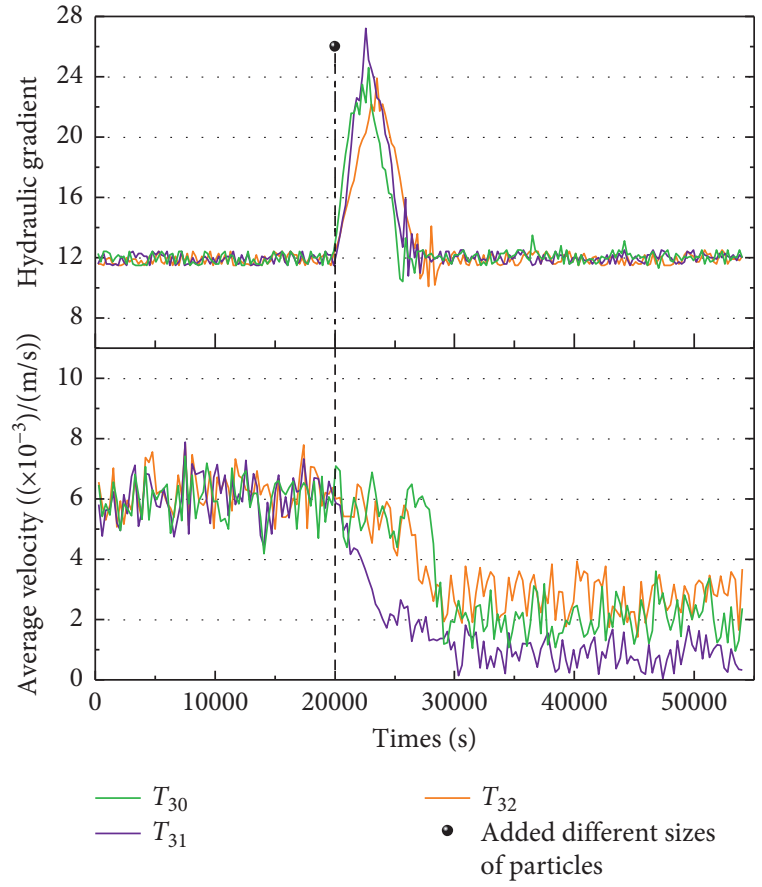

(f)

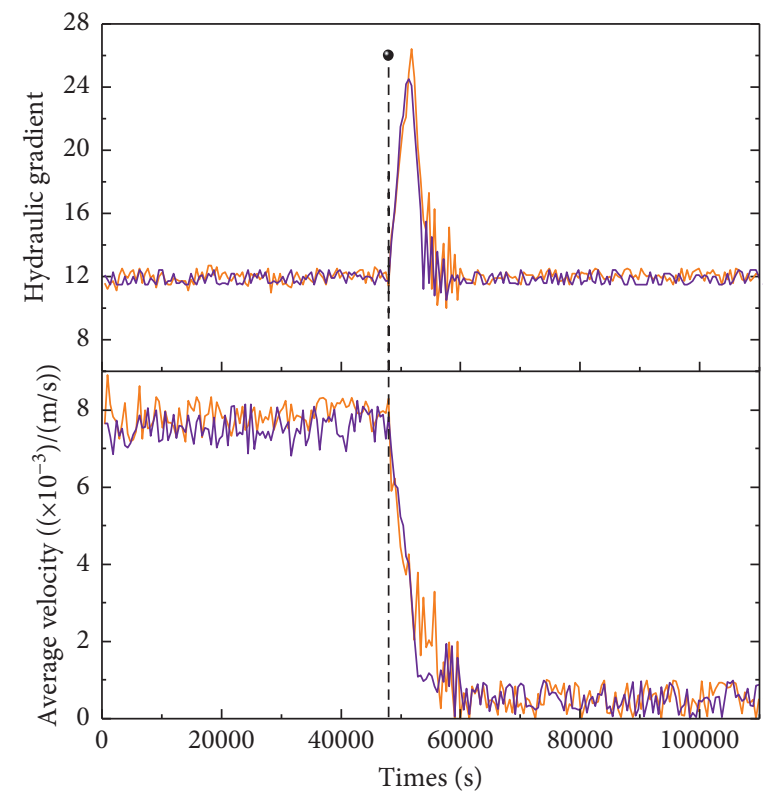

$-T_{33}$
$-T_{34}$
- $\quad$ Added different sizes of particles

(g)

FIgURE 3: Evolution of the hydraulic gradient and the flow velocity in six groups of soil media samples. (a) Soil media PS of 32-64 mm. (b) Soil media PS of 16-32 mm. (c) Soil media PS of 8-16 mm. (d) Soil media PS of 4-8 mm. (e) Soil media PS of 2-4 mm. (f) Soil media PS pf 1-2 mm. (g) Soil media PS of $0.5-1 \mathrm{~mm}$. 
some air is entrained into the sample column, which might cause fluctuations in the hydraulic gradient.

The initial flow velocity in the experimental columns of different soil media was found to vary around $25 \%$ within replicates (Figure 3). This can be attributed to the natural variability in media, and these observed variations were within the ranges reported in the literature, e.g., Sébastien et al. [43] around 49\% and Kandra et al. [20] around 30\% for different sand media.

The flow velocity remained relatively constant initially. It is logical that the larger the PS of the soil media is, the higher the initial stable flow velocity is. However, there were distinct differences in flow velocity after introducing incoming particles. For soil media of 2-4 mm (Figure 3(e)), the flow velocity decreased significantly after introducing particles of $0.125-0.25 \mathrm{~mm}, 0.25-0.5 \mathrm{~mm}$, and $0.5-1 \mathrm{~mm}$, especially $0.25-0.5 \mathrm{~mm}$. However, no changes were observed after introducing PSs of $0.063-0.125 \mathrm{~mm}$. A similar evolution of the flow velocity for the other six soil media is shown in Figure 3. This suggests that there is a clogging of particles in the sample column due to introducing different particle sizes.

A comparison of the flow velocity at the start and end of these experiments shows that the smaller the PS of the soil media is, the more obvious the variations in the flow velocity are; conversely, the variations in the flow velocity become more stable. A maximum decline was observed in the experiments of soil media PSs of $0.5-1 \mathrm{~mm}$ (Figure $3(\mathrm{~g})$ ), which results in an order of magnitude difference. This indicates that the particle size of soil media influences the properties of permeability and clogging.

3.1.2. Image Analysis. For porous media, like soil, physical clogging can be influenced by not only hydraulic characteristics but also porosity, size, type, and percent of fines [44]. For different PSs of soil media, due to smaller pore sizes of soil media than the size of the incoming particles, some incoming particles could not penetrate the pores; instead, they were mainly retained on the top of the soil media, forming a surface mat (Figure 4(a)). The particles could be transported by infiltration; however, some of them were trapped in the soil media (Figures 4(b) and 4(c)), while others were lost. Therefore, different PSs of incoming sediments can induce clogging of the soil column for different PSs of the soil media.

3.1.3. Sieve Analysis. For the same size of soil media particles, with incoming particles of different sizes, clogging changes with depth and thickness. To quantify the changes in the behavior of physical clogging due to incoming particles, relationships in the size of the soil media particles, the weight of the clogging particles, and accurate positions of the clogging were constructed, as shown in Figure 5. From top to bottom, the soil media in the sample column were divided into four layers by sieve analysis. The term $\alpha_{1}$ indicates the mass percentage of some incoming particle size in layer $i, \beta$ indicates the mass percentage of some incoming particle size in the collection column, and the total is $\sum \alpha_{i}+\beta=100 \%$.
Values of $\sum \alpha_{i}+\beta$ ranging from 96.3 to $99.1 \%$ are attributed to measurement errors in Table 2 .

From Figure 5, for different soil media particles, incoming sediments of the same PSs were trapped in different layers. For instance, sediments of PSs of $0.125-0.25 \mathrm{~mm}$ were concentrated on top of the soil media of PSs of $0.5-1 \mathrm{~mm}$ as in Figure 3(g), were clogged in layer 1 and layer 2 in the soil media of PSs of 1-2 mm shown in Figure 3(f), accumulated in layer 2, layer 3, and layer 4 in the soil media of PSs of 2-4 $\mathrm{mm}$ in Figure 3(e), and were lost from the soil media of PSs of 32-64 mm, 16-32 mm, 8-16 mm, and 4-8 $\mathrm{mm}$ shown in Figures 3(a)-3(d). Again, the mass percentage of incoming sediment clogging in different PSs of soil media was different. For instance, the mass percentage of sediments of PSs of $0.125-0.25 \mathrm{~mm}$ in layer 1 was $90.2 \%$ for soil media $0.5-1 \mathrm{~mm}$, the mass percentage in layer 1 and layer 2 was $79.4 \%$ for soil media $1-2 \mathrm{~mm}$, and the mass percentage for the sum or layer 1, layer 2, layer 3, and layer 4 was $77.1 \%$ for soil media $2-4 \mathrm{~mm}$. However, the mass percentage loss was $75 \%, 92.4 \%, 92.1 \%$, and $95.1 \%$ for soil media of $4-8 \mathrm{~mm}$, 8-16 mm, 16-32 mm, and 32-64 mm, respectively. Clogging for different PSs of incoming sediments in different soil media particles also suggests similar regularity, as shown in Table 2.

\subsection{Division of Clogging Patterns and Determination of the} Dominant Clogging Pattern. According to the sieve analysis, two results were found. First, four kinds of proportion characteristics of the mass percentage for different incoming sediment PSs clogging in different PSs of soil media were identified (Table 3-left). The mass percentage was determined by observations from Kandra et al. [20]. Clogging occurred if the incoming sediment mass percentage was more than $75 \%$. Second, four different clogging patterns were observed in different layers in the laboratory experiments, corresponding to the aforementioned mass percentage characteristics (Table 3). The idealized clogging was indicative of pure size exclusion, where clogging events occur only if particles enter a pore that is equal to their own diameter. However, soil pores were always inhomogeneous and anisotropic. We can, therefore, conclude that four different patterns were formed, which have been described in the image analysis results.

A comparison of the clogging patterns in the above seven experiments indicated that the mass percentage of incoming sediments forming surface clogging and surface-internal clogging patterns was $\alpha_{1}>\alpha_{2}>\alpha_{3}>\alpha_{4}$, and the mass percentage of incoming sediments forming an internal partial pore blockage pattern was $\alpha_{2}>\alpha_{3}>\alpha_{4}$. However, the mass percentage of incoming sediments forming an unclogging pattern was $\beta>\alpha_{4}>\alpha_{3}>\alpha_{2}>\alpha_{1}$. As expected, each clogging pattern developed a dominant layer. For the surface clogging and surface-internal clogging patterns, the dominant layer was layer 1, and layer 2 was dominant for the internal partial pore blockage pattern. Moreover, incoming sediments were lost for the unclogging pattern.

In addition, the flow velocity varied much for incoming sediments forming patterns of surface clogging, surface- 


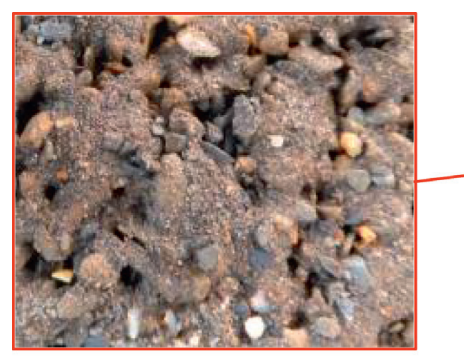

(a)

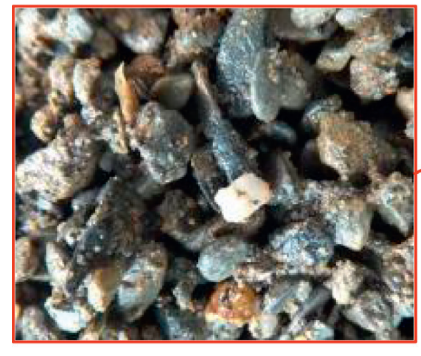

(c)

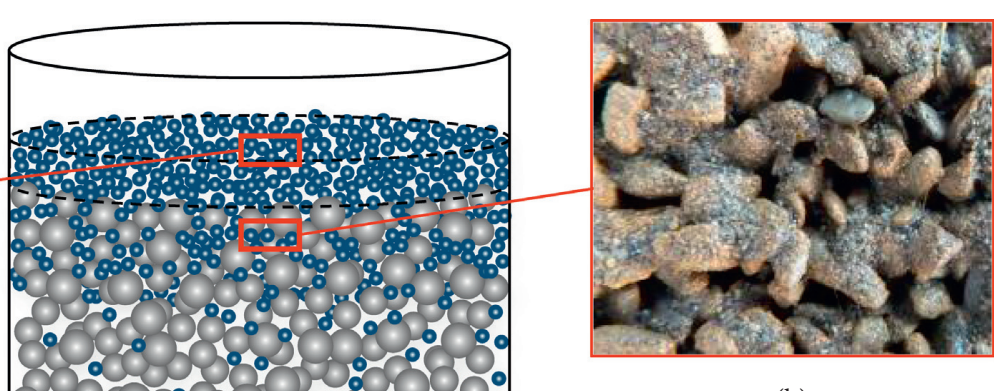

(b)

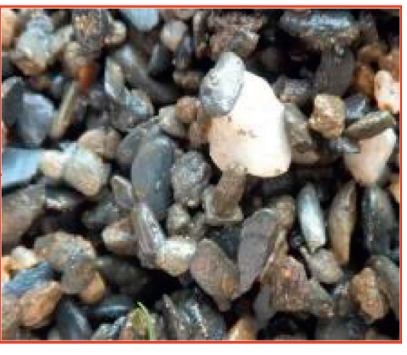

(d)

FIGURE 4: Images of soil media at different layers after experiment and soil media particles of size in 2-4 mm using USB DIGITAL MICROSCOPE. (a) Surface of the soil media. (b) Surface of layer 2. (c) Surface of layer 3. (d) Surface of layer 4.

internal clogging, and internal partial pore blockage, and the velocity was lower and variable for surface-internal clogging (Figure 3). At the same time, the hydraulic gradient for incoming sediments forming surface-internal clogging was slightly higher than that of the other two patterns (Figure 3 ). This indicates that the particles causing a lower flow velocity than the other size particles represented the dominant clogging particles, and the pattern of surface-internal clogging was the dominant clogging pattern. The dominant clogging PS for the soil media PSs of $16-32 \mathrm{~mm}$ was $2-4 \mathrm{~mm}$, for $8-16 \mathrm{~mm}$, it was $1-2 \mathrm{~mm}$, for $4-8 \mathrm{~mm}$, it was $0.5-1 \mathrm{~mm}$, for $2-4 \mathrm{~mm}$, it was $0.25-0.5 \mathrm{~mm}$, for $1-2 \mathrm{~mm}$, it was $0.125-0.25 \mathrm{~mm}$, and for $0.5-1 \mathrm{~mm}$, it was $0.063-0.125 \mathrm{~mm}$ (Table 2). Moreover, the 34 groups of experiments formed four patterns after being induced to incoming sediments of continuously graded soil, with only the soil media PSs of 32-64 $\mathrm{mm}$ not being representative of the surface-internal clogging pattern (Table 2). However, the clogging results showed that the flow velocity dropped and formed a surface clogging pattern. This is due to the lower head height and weaker carrying capacity of the water, while for incoming sediment PSs of 4-8 mm, sediment particles that were not transported accumulated on the surface of soil media PSs of 32-64 mm.

3.3. Assessment Criterion of Clogging Patterns and Determination of the Optimum Clogging PS. Based on the above analysis, we found that the relationship between soil media PSs and incoming sediment PSs affected the accurate classification of the clogging patterns. According to the relationship between them, a theoretical model was established.
3.3.1. Theoretical Analysis. The homogeneous soil is idealized as an ensemble of spheres of equal size, including various parallel capillary tubes (cylinders) of the same diameter that are equal to the natural soil pore. The pore is expressed as

$$
n=N\left(\frac{\pi D^{2}}{4}\right) \times 1
$$

where $D$ is the homogeneous soil pore size in the ideal state, $N$ denotes the number of capillary tubes per unit area, and $n$ is the porosity of natural soil. The number of capillary tubes per unit area, $N$, may be expressed as follows:

$$
N=\frac{4 n}{\pi D^{2}} \text {. }
$$

In an ideal state, the volume of homogeneous soil media is equal to the volume of natural soil media, written as follows:

$$
M \frac{\pi d^{3}}{6}=(1-n),
$$

where $M$ is the number of homogeneous soil media particles per unit volume, and $d$ is the size of homogeneous soil media particles in an ideal state.

Based on the above results, the area of the capillary tube wall can be taken as the area of the soil particle surface:

$$
\begin{gathered}
\mathrm{N} \pi \mathrm{D}=M \pi d^{2}, \\
M=N \frac{D}{d^{2}} .
\end{gathered}
$$

By combining equations (2), (3), and (5), D is solved as 


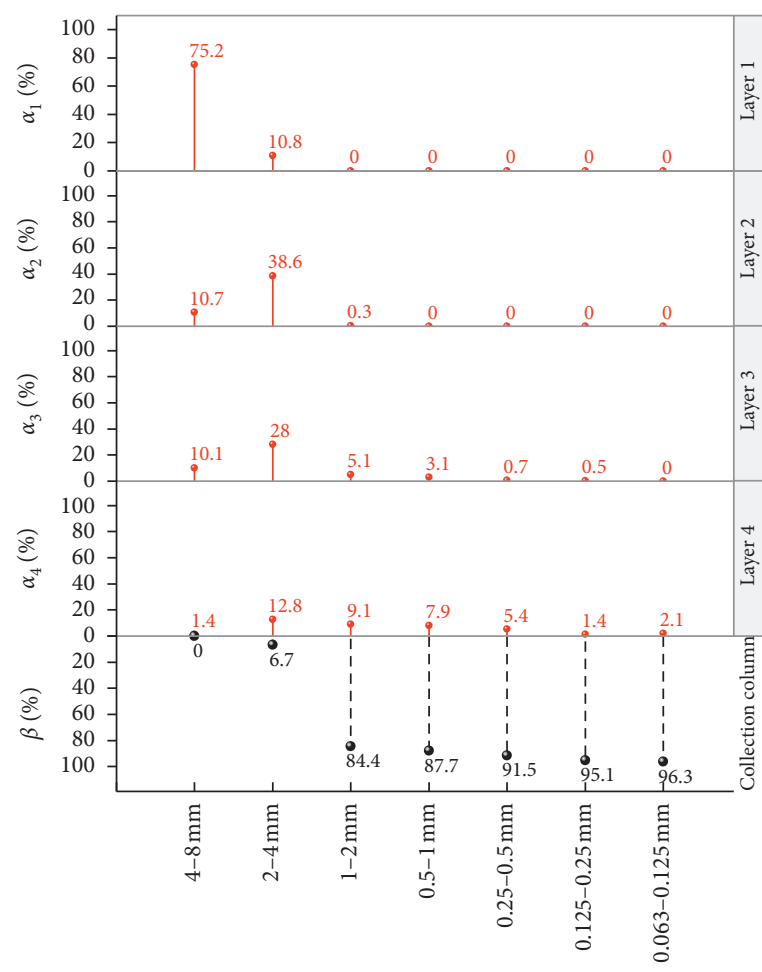

Added particle size (mm)

(a)

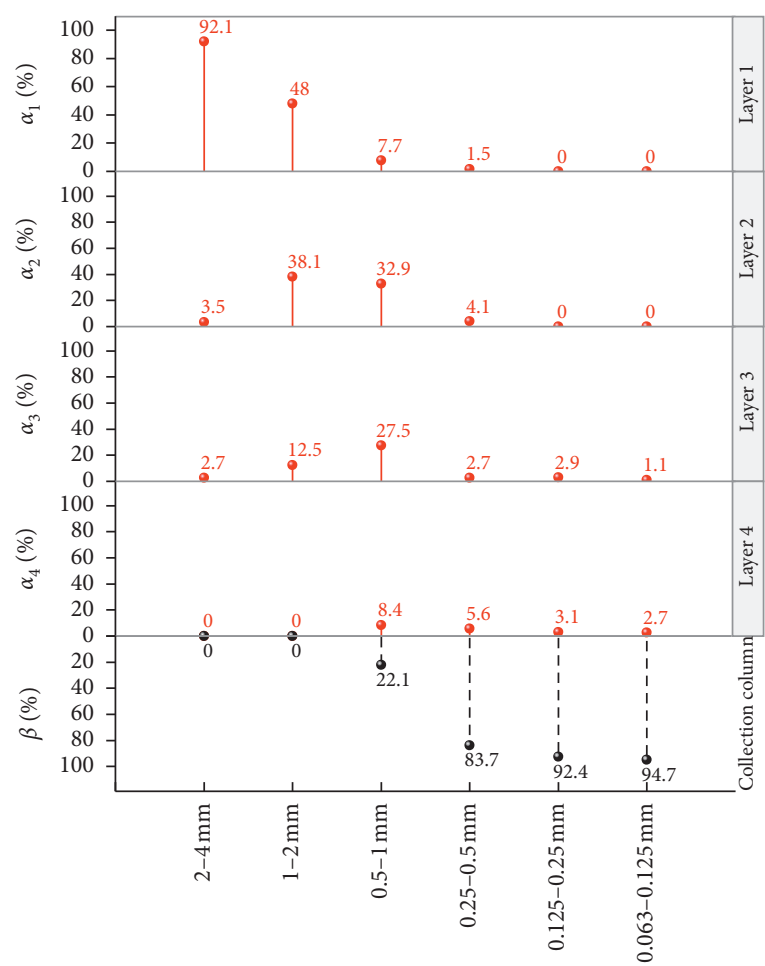

Added particle size (mm)

(c)

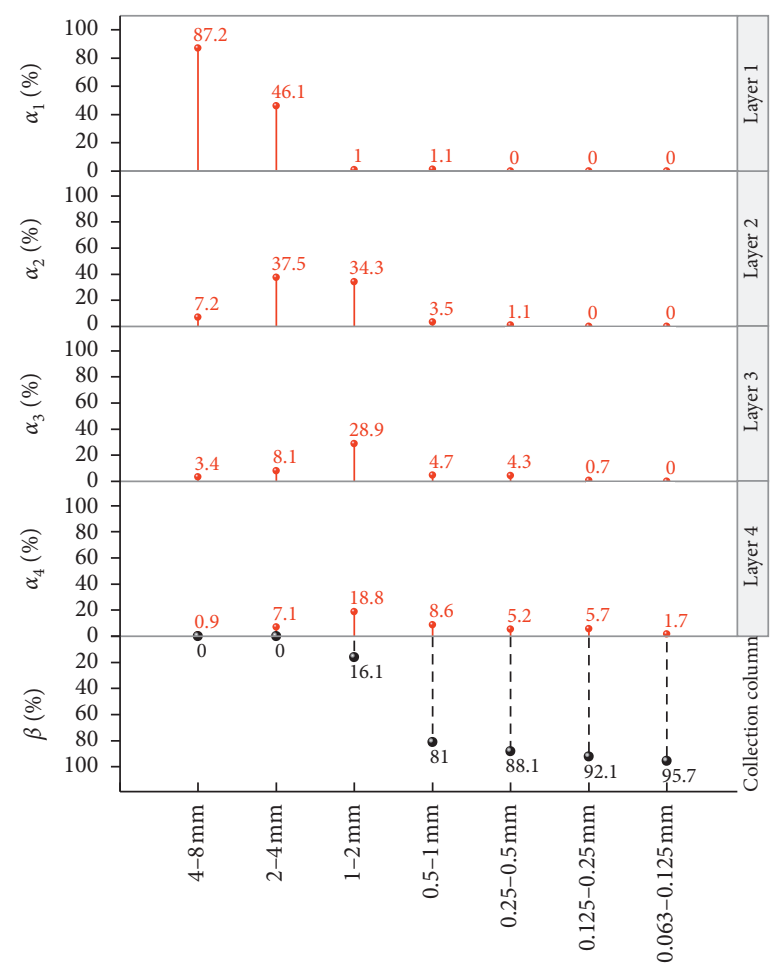

Added particle size (mm)

(b)

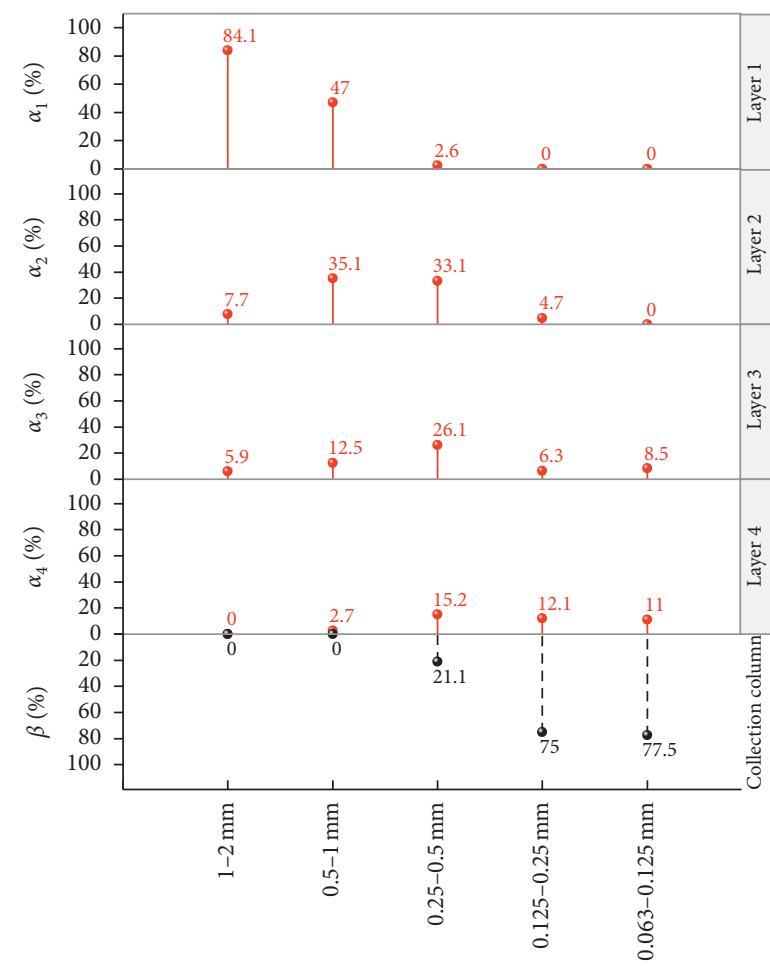

Added particle size (mm)

(d)

Figure 5: Continued. 


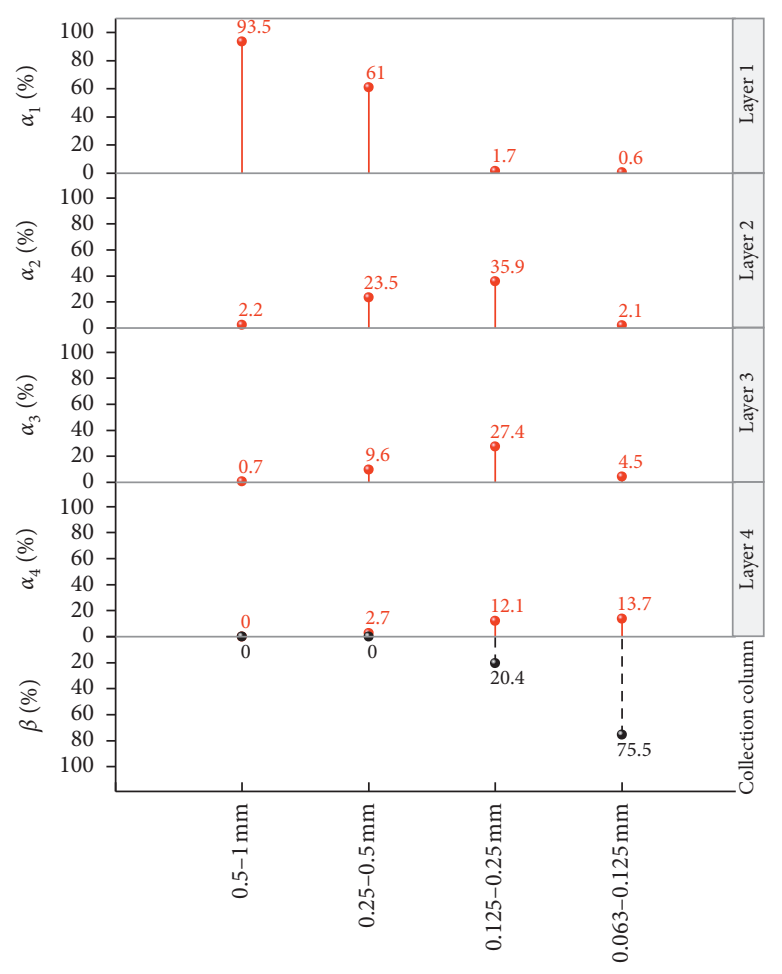

Added particle size $(\mathrm{mm})$

(e)

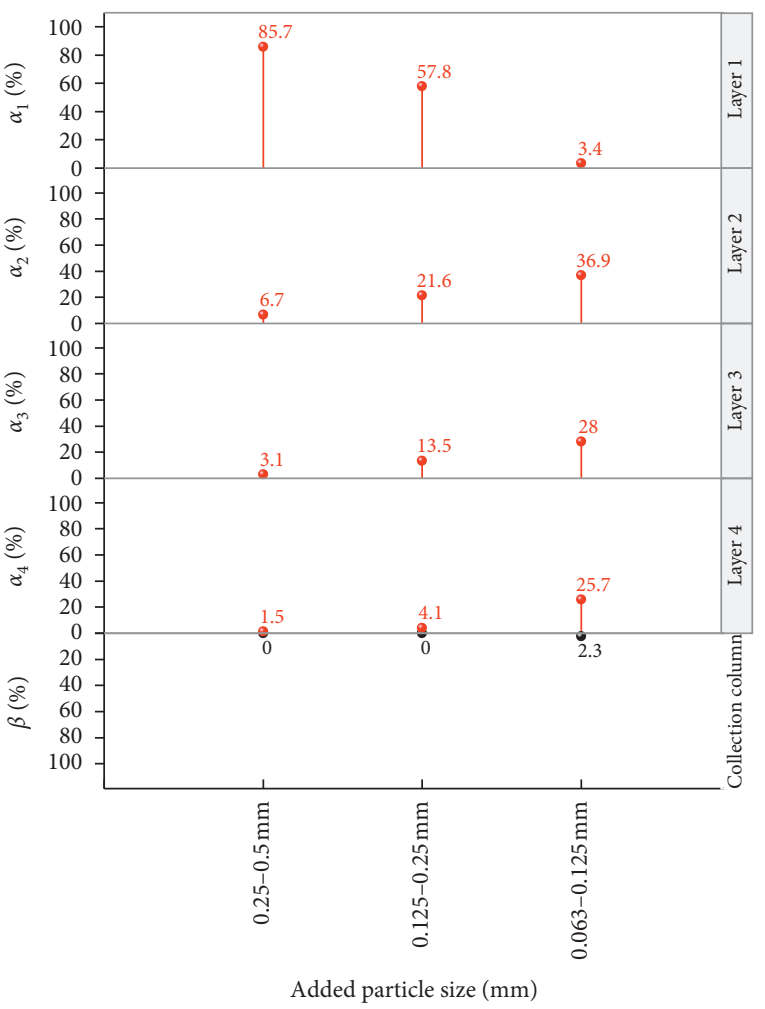

(f)

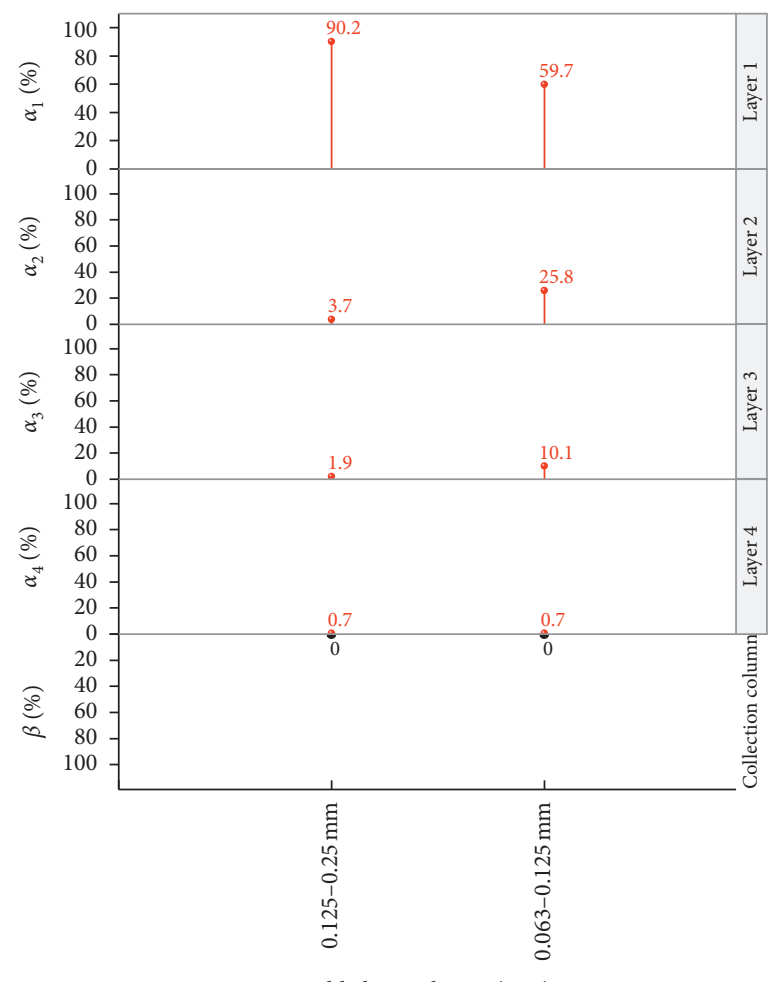

Added particle size (mm)

(g)

FIGURE 5: Mass percentage of clogging particles in four layers and loss in the collection column in six groups of soil media samples. (a) Soil media PSs of 32-64 mm. (b) Soil media PSs of 16-32 mm. (c) Soil media PSs of 8-16 mm. (d) Soil media PSs of 4-8 mm. (e) Soil media PSs of 2-4 mm. (f) Soil media PSs of 1-2 mm. (g) Soil media PSs of $0.5-1 \mathrm{~mm} . \alpha_{i}=\left(m_{i} / m_{0}\right) \times 100 \%$; $m_{i}$ is the mass of the incoming particles of some size in layer I, $\mathrm{kg} ; m_{0}$ is the total mass of incoming particles of some size, $\mathrm{kg} ; \beta=\left(m_{m} / m_{0}\right) \times 100 \%$; and $m_{m}$ is the mass of incoming particles of some size in the collection column, $\mathrm{kg}$. 


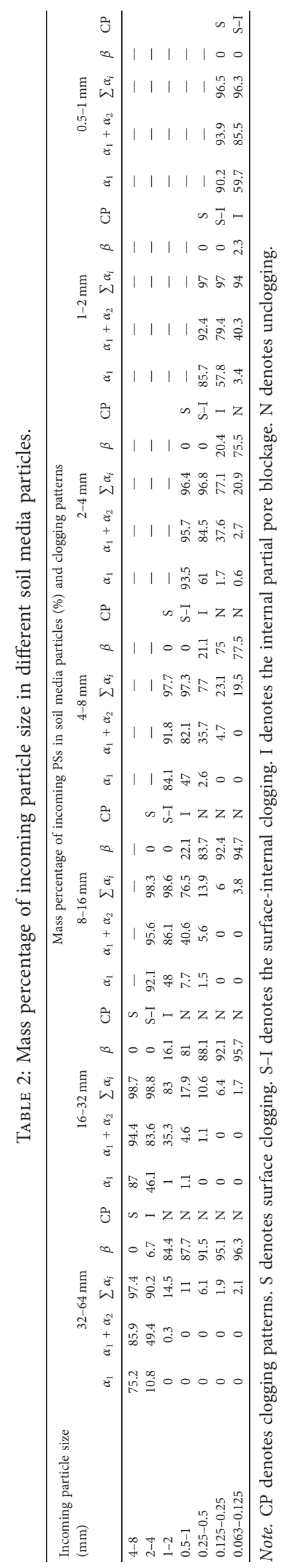


Table 3: Mass percentage of incoming PSs in different soil media particles.

Proportion characteristics of mass percentage for different incoming sediments in size clogging for different soil skeletons in size

Clogging patterns

$\alpha_{1}$ is greater than $75 \%$

$\alpha_{1}$ is less than $75 \%$ and the sum of $\alpha_{1}$ and $\alpha_{2}$ is greater than $75 \%$

$S$

Sum of $\alpha_{1}$ and $\alpha_{2}$ is less than $75 \%$ and the sum of $\alpha_{1}, \alpha_{2}, \alpha_{3}$, and $\alpha_{4}$ is greater than $75 \%$

S-I

$\beta$ is greater than $75 \%$

I

Note. S denotes surface clogging. S-I denotes surface-internal clogging. I denotes internal partial pore blockage. $\mathrm{N}$ denotes unclogging.

$$
D=\frac{2}{3}\left(\frac{n}{1-n}\right) d
$$

Indeed, each soil particle is an inhomogeneous sphere, the pores formed by soil media particles are also uneven, and the incoming particles are inhomogeneous too. We can choose the equivalent size of soil particles and an effective aperture formed by soil particle pores to substitute inhomogeneous soil particles and their formed voids. For each PS range, the equivalent size was calculated by the particle geometric average:

$$
D_{e}=\sqrt{D_{\max } D_{\min }}
$$

where $D_{e}$ denotes the equivalent size of the soil particles, $D_{\max }$ is the maximum PS, and $D_{\min }$ is the minimum PS.

The effective aperture of soil is then calculated as follows:

$$
D_{\text {ea }}=\frac{2}{3 \alpha_{1}}\left(\frac{n_{s}}{1-n_{s}}\right) D_{e},
$$

where $D_{\text {ea }}$ denotes the effective aperture of the soil, $n_{s}$ is the porosity of the soil equal to $n$, and $\alpha_{1}$ is a particle shape correction factor equal to the ratio of soil particle surface area and sphere surface area in the same volume for ideal sand and gravel materials: $\alpha_{1}=1.5-1.9$ [45].

3.3.2. Assessment Criterion of Clogging Patterns. The equivalent size of soil media particles and incoming particles was calculated using equation (7) to derive $D_{e}$ and $d_{e}$, and the effective aperture $D_{\text {ea }}$ was calculated using equation (8). Then, the ratio of $d_{e}$ and $D_{\text {ea }}$ was obtained. Assuming that the soil particles are spheres of equal size, it is logical that when the ratio of the incoming particle size and the pore size is greater than 1, a mat is formed on the surface of the soil media. Moreover, when the ratio is equal to 1 , clogging occurs, and when the ratio is less than 1, incoming particles will penetrate the pores and be lost. However, as already discussed, the soil particles and pores were not uniform in shape or size, as shown in Table 3. Clogging was formed when the $\left(d_{e} / D_{\text {ea }}\right)$ ratio was less than 1 , as shown in Table 4. A similar situation was previously observed in wetland tests by Hua et al. [46], where clogging was observed for particles entering pores of a smaller diameter.

According to the results of six groups of soil media PSs from $0.5 \mathrm{~mm}$ to $32 \mathrm{~mm}$, if we hypothesized that the criteria of $0.5<\left(d_{e} / D_{\mathrm{ea}}\right) \leq 1$ were representative of the surface-internal clogging pattern, knowing the PS and porosity of the soil media and using equation (8), the clogging PS $d_{\mathrm{et}}$ could be obtained by calculating $d_{o}$ as follows:

$$
\frac{n}{3 \alpha_{1}(1-n)} D_{e}<d_{o} \leq \frac{2 n}{3 \alpha_{1}(1-n)} D_{e}
$$

where $d_{o}$ denotes the clogging PS that results in the surfaceinternal clogging pattern. The calculation results agree well with the dominant clogging PS of the surface-internal clogging pattern in the laboratory (Figure 6(a)).

The other three criteria were assumed to be represented by $\left(d_{e} / D_{\mathrm{ea}}\right)>1$ for the surface clogging pattern, $0.25<\left(d_{e} / D_{\text {ea }}\right) \leq 0.5$ for the internal partial pore blockage pattern, and $\left(d_{e} / D_{\text {ea }}\right) \leq 0.25$ for representing the unclogging pattern. The mathematical expressions for these relations are as follows:

$$
d_{\mathrm{sc}}>\frac{2 n}{3 \alpha_{1}(1-n)} D_{\mathrm{e}}
$$

$$
\begin{gathered}
\frac{n}{6 \alpha_{1}(1-n)} D_{e} \leq d_{\mathrm{ic}}<\frac{n}{3 \alpha_{1}(1-n)} D_{e} \\
d_{\mathrm{uc}}<\frac{n}{6 \alpha_{1}(1-n)} D_{e},
\end{gathered}
$$

where $d_{\mathrm{sc}}$ denotes the PS forming the surface clogging pattern, $d_{\mathrm{ic}}$ denotes the PS forming the internal partial pore blockage pattern, and $d_{\mathrm{uc}}$ denotes the PS not resulting in clogging. The calculation results of the above four criteria confirmed the correspondence between the $\left(d_{e} / D_{\text {ea }}\right)$ ratio and the four clogging patterns (Figure 6). Therefore, the dependence of the clogging pattern on the $\left(d_{e} / D_{\text {ea }}\right)$ ratio is shown in Table 5.

In addition, for soil media PSs of $32-64 \mathrm{~mm}$ and incoming PSs of $4-8 \mathrm{~mm}$, the calculation result was consistent with the surface-internal clogging pattern, although the surface clogging pattern was observed in the laboratory. This difference may be explained by the lower head height and weaker carrying capacity of the water, as discussed in Section 3.2. This implies that it is more difficult for larger pore structure media to form clogs, as observed by Hua et al. [46]. Furthermore, for soil media PSs of $0.5-1 \mathrm{~mm}$ and $1-2 \mathrm{~mm}$, no unclogging pattern was observed after feeding the particles, which has also been reported in the literature, e.g., Wang [19] and Fetzer et al. [47]. The observations eventually resulted in the above criteria, which are more suitable for smaller PS pebbles and gravel and larger PS sand.

3.3.3. Optimum Clogging PS. The calculated clogging PSs for different clogging patterns were compared with the data observed in the laboratory (Figure 6). The calculated results 
TABLE 4: Calculation results.

\begin{tabular}{|c|c|c|c|c|c|c|c|}
\hline$D_{s}(\mathrm{~mm})$ & $D_{e}(\mathrm{~mm})$ & $n_{s}$ & $D_{\text {ea }}(\mathrm{mm})$ & $d_{a}(\mathrm{~mm})$ & $d_{e}(\mathrm{~mm})$ & $d_{e} / D_{\mathrm{ea}}$ & Clogging patterns from the experimental observations \\
\hline \multirow{7}{*}{$32 \sim 64$} & \multirow{7}{*}{45.255} & \multirow{7}{*}{0.326} & \multirow{7}{*}{$7.68-9.73$} & $4-8$ & 5.66 & $0.58-0.74$ & S \\
\hline & & & & $2-4$ & 2.83 & $0.29-0.37$ & $\mathrm{I}$ \\
\hline & & & & $1-2$ & 1.41 & $0.15-0.18$ & $\mathrm{~N}$ \\
\hline & & & & $0.5-1$ & 0.71 & $0.07-0.09$ & $\mathrm{~N}$ \\
\hline & & & & $0.25-0.5$ & 0.36 & $0.04-0.05$ & $\mathrm{~N}$ \\
\hline & & & & $0.125-0.25$ & 0.18 & $0.02-0.03$ & $\mathrm{~N}$ \\
\hline & & & & $0.063-0.125$ & 0.09 & $0.01-0.02$ & $\mathrm{~N}$ \\
\hline \multirow{7}{*}{$16 \sim 32$} & \multirow{7}{*}{22.627} & \multirow{7}{*}{0.310} & \multirow{7}{*}{$3.57-4.52$} & $4-8$ & 5.66 & $1.25-1.59$ & $\mathrm{~S}$ \\
\hline & & & & $2-4$ & 2.83 & $0.63-0.79$ & S-I \\
\hline & & & & $1-2$ & 1.41 & $0.31-0.40$ & I \\
\hline & & & & $0.5-1$ & 0.71 & $0.15-0.20$ & $\mathrm{~N}$ \\
\hline & & & & $0.25-0.5$ & 0.36 & $0.07-0.10$ & $\mathrm{~N}$ \\
\hline & & & & $0.125-0.25$ & 0.18 & $0.03-0.05$ & $\mathrm{~N}$ \\
\hline & & & & $0.063-0.125$ & 0.09 & $0.01-0.03$ & $\mathrm{~N}$ \\
\hline \multirow{6}{*}{$8 \sim 16$} & \multirow{6}{*}{11.314} & \multirow{6}{*}{0.290} & \multirow{6}{*}{$1.62-2.05$} & $2-4$ & 2.83 & $1.38-1.74$ & $S$ \\
\hline & & & & $1-2$ & 1.41 & $0.69-0.87$ & S-I \\
\hline & & & & $0.5-1$ & 0.71 & $0.34-0.44$ & I \\
\hline & & & & $0.25-0.5$ & 0.35 & $0.17-0.22$ & $\mathrm{~N}$ \\
\hline & & & & $0.125-0.25$ & 0.16 & $0.08-0.11$ & $\mathrm{~N}$ \\
\hline & & & & $0.063-0.125$ & 0.08 & $0.04-0.06$ & $\mathrm{~N}$ \\
\hline \multirow{5}{*}{$4 \sim 8$} & \multirow{5}{*}{5.657} & \multirow{5}{*}{0.307} & \multirow{5}{*}{$0.88-1.11$} & $1-2$ & 1.41 & $1.27-1.60$ & $S$ \\
\hline & & & & $0.5-1$ & 0.71 & $0.63-0.80$ & S-I \\
\hline & & & & $0.25-0.5$ & 0.35 & $0.31-0.40$ & I \\
\hline & & & & $0.125-0.25$ & 0.18 & $0.15-0.20$ & $\mathrm{~N}$ \\
\hline & & & & $0.063-0.125$ & 0.09 & $0.07-0.10$ & $\mathrm{~N}$ \\
\hline \multirow{4}{*}{$2 \sim 4$} & \multirow{4}{*}{2.828} & \multirow{4}{*}{0.340} & \multirow{4}{*}{$0.51-0.65$} & $0.5-1$ & 0.71 & $1.09-1.39$ & $S$ \\
\hline & & & & $0.25-0.5$ & 0.35 & $0.54-0.69$ & S-I \\
\hline & & & & $0.125-0.25$ & 0.18 & $0.27-0.35$ & I \\
\hline & & & & $0.063-0.125$ & 0.089 & $0.13-0.18$ & $\mathrm{~N}$ \\
\hline \multirow{3}{*}{$1 \sim 2$} & \multirow{3}{*}{1.414} & \multirow{3}{*}{0.332} & \multirow{3}{*}{$0.25-0.31$} & $0.25-0.5$ & 0.35 & $1.13-1.40$ & $S$ \\
\hline & & & & $0.125-0.25$ & 0.18 & $0.58-0.72$ & S-I \\
\hline & & & & $0.063-0.125$ & 0.089 & $0.29-0.36$ & I \\
\hline \multirow{2}{*}{$0.5 \sim 1$} & \multirow{2}{*}{0.707} & \multirow{2}{*}{0.335} & \multirow{2}{*}{$0.125-0.16$} & $0.125-0.25$ & 0.18 & $1.13-1.44$ & $\mathrm{~S}$ \\
\hline & & & & $0.063-0.125$ & 0.089 & $0.56-0.72$ & S-I \\
\hline
\end{tabular}

Note. $D_{s}$ denotes soil skeleton particle size. $D_{a}$ denotes incoming particle size. $D_{e}$ is the equivalent size of soil skeleton particles. $D_{e}$ denotes the equivalent size of incoming particles. ns is the porosity of the soil skeleton. $\alpha_{1}$ is the particle shape correction factor. Dea is the effective aperture of soil in different $\alpha_{1}$.

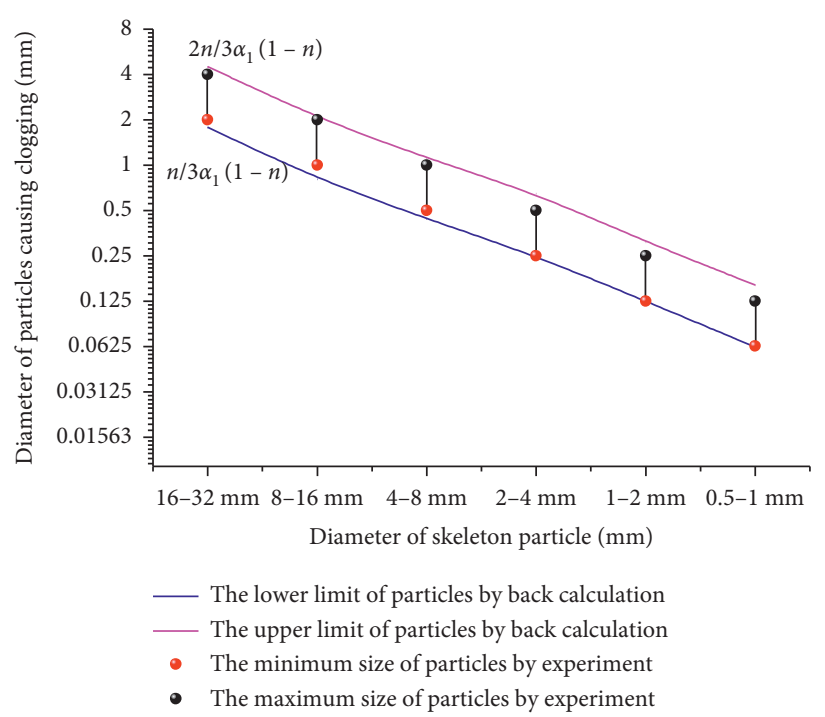

(a)

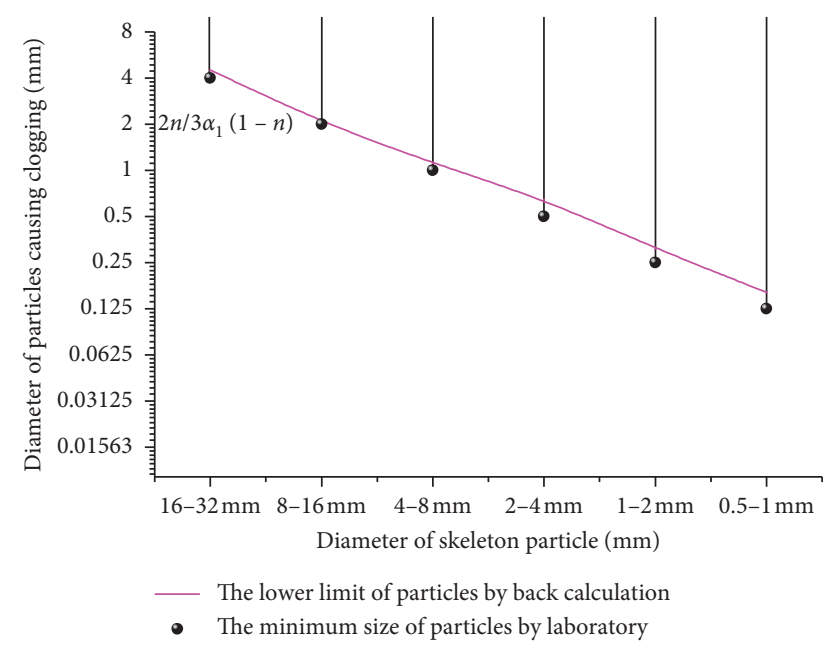

(b)

FIGURE 6: Continued. 


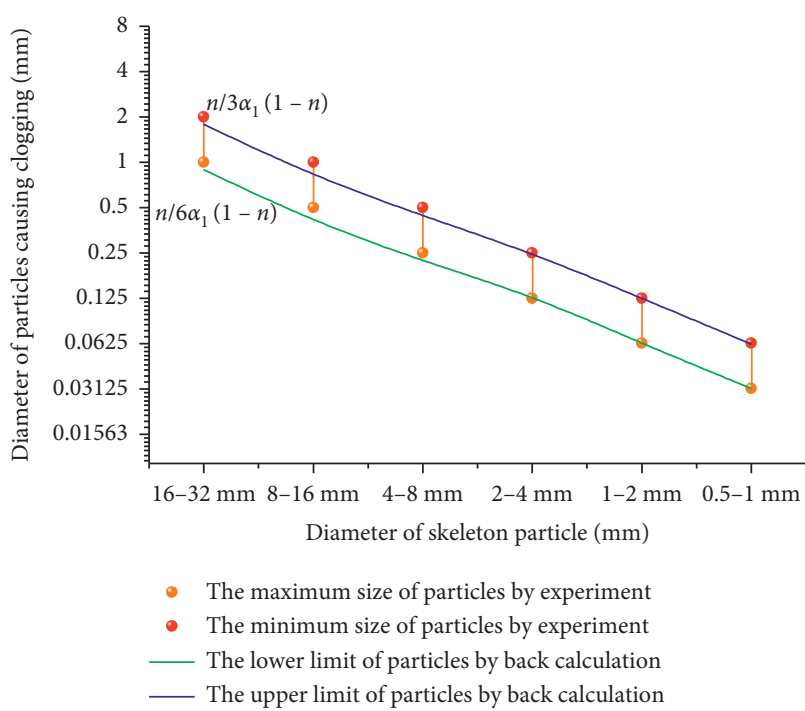

(c)

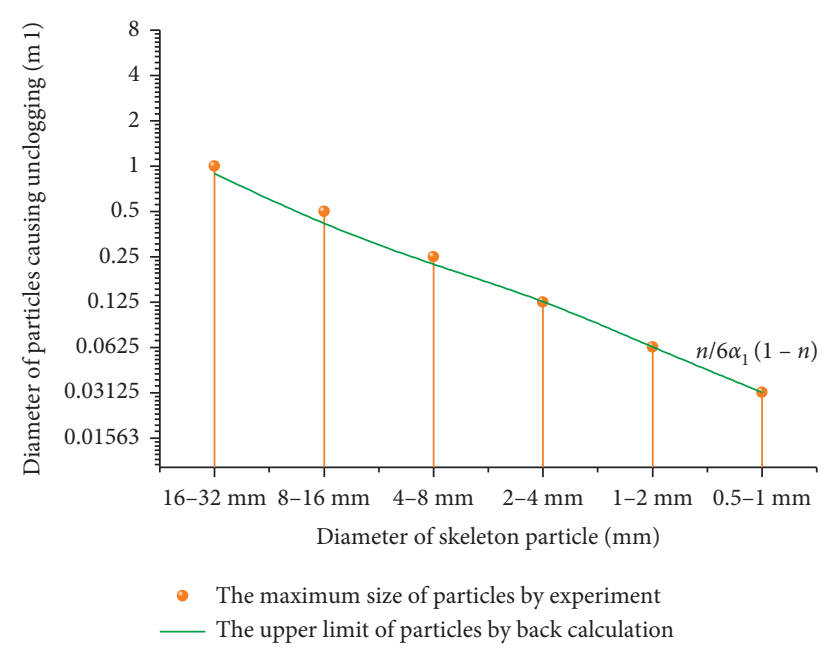

(d)

FIGURE 6: Clogging particle size for different soil media by calculation and experimental observation. (a) Surface-internal clogging pattern. (b) Surface clogging pattern. (c) Internal partial pore blockage pattern. (d) Unclogging pattern.

TABLE 5: Criteria for determining the clogging patterns of unisize-graded soils.

\begin{tabular}{|c|c|c|c|c|}
\hline$d_{e} / D_{\mathrm{ea}}$ & $>1$ & $0.5-1$ & $0.25-0.5$ & $<0.25$ \\
\hline Clogging patterns & Surface clogging & Surface-internal clogging & Internal partial pore blockage & Unclogging \\
\hline
\end{tabular}

Note. $\mathrm{d}_{e}$ denotes the equivalent size of incoming particles. $\mathrm{D}_{\mathrm{ea}}$ denotes the effective aperture of soil.

using the inequalities in equation (9) showed the best agreement with the observed clogging PS in the laboratory, which can be adopted to estimate the optimum clogging PS. Ultimately, $d$ was confirmed as the optimum clogging PS, and $0.5<\left(d_{e} / D_{\text {ea }}\right) \leq 1$ was used as the assessment criterion of the optimum clogging pattern.

\section{Conclusions}

A lab-based approach was carried out by studying the effects of the PS and the effective aperture of soil on the clogging performance in highly permeable coarse soil of dam foundations. The results showed that due to the soil particles and pores being inhomogeneous in shape or size, four different clogging patterns were formed in the studied coarse soil. The assessment criterion of clogging patterns can be depicted through the $\left(d_{e} / D_{\mathrm{ea}}\right)$ ratio as follows:

(i) $\left(d_{e} / D_{\text {ea }}\right)>$ for surface clogging

(ii) $0.5<\left(d_{e} / D_{\text {ea }}\right) \leq 1$ for surface-internal clogging

(iii) $0.25<\left(d_{e} / D_{\text {ea }}\right) \leq 0.5$ for internal partial pore blockage

(iv) $\left(d_{e} / D_{\text {ea }}\right) \leq 0.25$ for unclogging

Due to the lower head height and weaker carrying capacity of the water, leading to the above criteria being more suitable for pebbles and gravels of smaller PSs and sand of larger PSs, for the soil media larger than $32 \mathrm{~mm}$, most of the incoming particles were lost.

Moreover, from the results of experiments and formula calculations, surface-internal clogging was the optimum clogging pattern. The optimum clogging particle in the pattern of surface-internal clogging was confirmed by the following:

$$
\frac{n}{3 \alpha_{1}(1-n)} D_{e}<d_{o} \leq \frac{2 n}{3 \alpha_{1}(1-n)} D_{e}
$$

The classification of clogging patterns, the calculation of the optimum clogging PS, and the determination of the equivalent PS can provide an effective way to study shrinking leakage problems in highly permeable coarse soil of dam foundations.

\section{Data Availability}

The data used to support the findings of this study are included within the article.

\section{Disclosure}

Jianquan $\mathrm{Ma}$ is responsible for this article.

\section{Conflicts of Interest}

The authors declare that there are no conflicts of interest regarding the publication of this paper.

\section{Authors' Contributions}

Jianquan Ma and Shibo Li designed experiments; Hao Peng, Shibo Li, and Xinshe Zhang carried out experiments; Hao Peng analyzed experimental results; Jianquan Ma assisted 
with the conceptualization of the study and the data interpretations; Shibo Li drew figures. All authors provided valuable critical revisions of the manuscript and also agreed to both contents and form of the final version.

\section{Acknowledgments}

This work was supported by the National Natural Science Foundation of China (Nos. 41602359, 41907255, 41702298, and 41807190) and the Natural Science Basic Research Plan in Shaanxi Province of China (Nos. 2017JQ4019 and 2017JQ4020). The authors would like to thank Professor Changming Wang and Professor Gangcheng Wang, Construction Engineering College of Jilin University, for the technical support provided for this research.

\section{References}

[1] C. S. Dubey, K. Venkatachalam, M. Ratnam, and P. Shekhar, "Causes of seepage water in drainage and grouting galleries of the Pandoh dam, Central Himalaya," Bulletin of Engineering Geology and the Environment, vol. 63, no. 1, pp. 19-23, 2004.

[2] G. Berhane, K. Martens, N. Al Farrah, and K. Walraevens, "Water leakage investigation of micro-dam reservoirs in Mesozoic sedimentary sequences in Northern Ethiopia," Journal of African Earth Sciences, vol. 79, pp. 98-110, 2013.

[3] Y.-F. Chen, J.-M. Hong, H.-K. Zheng, Y. Li, R. Hu, and C.-B. Zhou, "Evaluation of groundwater leakage into a drainage tunnel in Jinping-I arch dam foundation in Southwestern China: a case study," Rock Mechanics and Rock Engineering, vol. 49, no. 3, pp. 961-979, 2016.

[4] M. MozafariE, R. J. Guerrero, and J. S. Guerrero, "Contribution of spectral coherency analysis and tracer test to study leakage at the Doosti dam reservoir, Iran and Turkmenistan," Environmental Earth Sciences, vol. 77, no. 4, p. 139, 2018.

[5] G. C. Wang and C. Huang, "Seepage analysis for dam foundation and abutment of Jiangxiong reservior and its leakage-proof plan evaluation," Global Geology, vol. 28, no. 3, pp. 367-370, 2009.

[6] S. B. Li, C. M. Wang, T. T. Zou et al., "Test and mechanism of seepage deformation for the looses dam foundation in the Shannan region of Tibet," Hydrogeology \& Engineering Geology, vol. 43, no. 1, pp. 57-63, 2016.

[7] L. Ke and A. Takahashi, "Experimental investigations on suffusion characteristics and its mechanical consequences on saturated cohesionless soil," Soils and Foundations, vol. 54, no. 4, pp. 713-730, 2014.

[8] J. S. Walder, R. M. Iverson, J. W. Godt, M. Logan, and S. A. Solovitz, "Controls on the breach geometry and flood hydrograph during overtopping of noncohesive earthen dams," Water Resources Research, vol. 51, no. 8, pp. 6701-6724, 2015.

[9] M. Foster, R. Fell, and M. Spannagle, "The statistics of embankment dam failures and accidents," Canadian Geotechnical Journal, vol. 37, no. 5, pp. 1000-1024, 2000.

[10] S. Messerklinger, "Failure of a geomembrane lined embankment dam-case study," Geotextiles and Geomembranes, vol. 42, no. 3, pp. 256-266, 2014.

[11] G. H. Wei, "Application of transient surface wave technology in seepage reconnaissance of Tibet Qiongguo reservoir," Water Resouices \& Hydropower of Northeast China, vol. 21, no. 9, pp. 51-52, 2003.
[12] G. J. Zhang, "Experimental study of clogging effect on permeability of dam foundation soil for Plateau reservoir," Master thesis, Jilin university, Changchun, China, 2008.

[13] N. Jiang, "An application of curtain grouting in seepage prevention treament of dam foundation of Awoduo reservoir in Tibet," Master thesis, Jilin university, Changchun, China, 2014.

[14] T. Datry, N. Lamouroux, G. Thivin, S. Descloux, and J. M. Baudoin, "Estimation of sediment hydraulic conductivity in river reaches and its potential use to evaluate streambed clogging," River Research and Applications, vol. 31, no. 7, pp. 880-891, 2015.

[15] A. Seghir, A. Benamar, and H. Wang, "Effects of fine particles on the suffusion of cohesionless soils experiments and modeling," Transport in Porous Media, vol. 103, no. 2, pp. 233-247, 2014.

[16] A. Alem, N.-D. Ahfir, A. Elkawafi, and H. Q. Wang, "Hydraulic operating conditions and particle concentration effects on physical clogging of a porous medium," Transport in Porous Media, vol. 106, no. 2, pp. 303-321, 2015.

[17] M. Sato and R. Kuwano, "Laboratory testing for evaluation of the influence of a small degree of internal erosion on deformation and stiffness," Soils and Foundations, vol. 58, no. 3, pp. 547-562, 2018.

[18] J. Sansalone, X. Kuang, G. Ying, and V. Ranieri, "Filtration and clogging of permeable pavement loaded by urban drainage," Water Research, vol. 46, no. 20, pp. 6763-6774, 2012.

[19] Z. J. Wang, X. Q. Du, Y. S. Yang, and X. Ye, "Surface clogging process modeling of suspended solids during urban stormwater aquifer recharge," Journal of Environmental Sciences, vol. 24, no. 8, pp. 1418-1424, 2012.

[20] H. S. Kandra, D. McCarthy, T. D. Fletcher, and A. Deletic, "Assessment of clogging phenomena in granular filter media used for stormwater treatment," Journal of Hydrology, vol. 512, pp. 518-527, 2014.

[21] O. S. Q. Yousif, M. Karakouzian, N. O. A. Rahim, and K. A. Rashed, "Physical clogging of uniformly graded porous media under constant flow rates," Transport in Porous Media, vol. 120, no. 3, pp. 643-659, 2017.

[22] G. Zheng, J. R. Cao, X. S. Cheng, D. Ha, and F. J. Wang, "Experimental study on the artificial recharge of semiconfined aquifers involved in deep excavation engineering," Journal of Hydrology, vol. 557, pp. 868-877, 2018.

[23] K. Barry, J. Vanderzalm, K. Miotlinski, and P. Dillon, "Assessing the impact of recycled water quality and clogging on infiltration rates at a pioneering soil aquifer treatment (SAT) site in alice springs, northern territory (NT), Australia," Water, vol. 9, no. 3, p. 179, 2017.

[24] M. Tong and W. P. Johnson, "Excess colloid retention in porous media as a function of colloid size, fluid velocity, and grain angularity," Environmental Science \& Technology, vol. 40 , no. 24, pp. 7725-7731, 2006.

[25] B. E. Hatt, T. D. Fletcher, and A. Deletic, "Hydraulic and pollutant removal performance of fine media stormwater filtration systems," Environmental Science \& Technology, vol. 42, no. 7, pp. 2535-2541, 2008.

[26] J. Wu, Y. Wu, J. Lu, and L. Lee, "Field investigations and laboratory simulation of clogging in Lixi tailings dam of Jinduicheng, China," Environmental Geology, vol. 53, no. 2, pp. 387-397, 2007.

[27] J. Wu, Y. Wu, and J. Lu, "Laboratory study of the clogging process and factors affecting clogging in a tailings dam," Environmental Geology, vol. 54, no. 5, pp. 1067-1074, 2008. 
[28] R. L. Beschta and W. L. Jackson, "The intrusion of fine sediments into a stable gravel bed," Journal of the Fisheries Research Board of Canada, vol. 36, no. 2, pp. 204-210, 1979.

[29] G. Khaddour, I. Riedel, E. Andò et al., "Grain-scale characterization of water retention behaviour of sand using X-ray CT," Acta Geotechnica, vol. 13, no. 3, pp. 497-512, 2018.

[30] R. McIsaac and R. K. Rowe, "Clogging of gravel drainage layers permeated with landfill leachate," Journal of Geotechnical and Geoenvironmental Engineering, vol. 133, no. 8, pp. 1026-1039, 2007.

[31] J. Liu, Seepage Control of Earth-Rock Dams Theoretical Basis, Engineering Experiences and Lessons, China Water \& Power Press, Beijing, China, 1st edition, 2006.

[32] S. B. Li, Mechanism of infiltration-clogging and test for plateau dam foundation, Ph.D. Dissertation, Jilin University, Changchun, China, 2014.

[33] U. Schälchli, B. T. Hart and P. G. Sly, "The clogging of coarse gravel river beds by fine sediment," in Sediment/Water Interactions, vol. 235-236, no. 1, pp. 189-197, Kluwer Academic Publishers, Berlin, Germany, 1992.

[34] L. M. McDowell-Boyer, J. R. Hunt, and N. Sitar, "Particle transport through porous media," Water Resources Research, vol. 22, no. 13, pp. 1901-1921, 1986.

[35] I. R. Fleming, R. K. Rowe, and D. R. Cullimore, "Field observations of clogging in a landfill leachate collection system," Canadian Geotechnical Journal, vol. 36, no. 4, pp. 685-707, 1999.

[36] S. Pal and K. Deb, "Effect of clogging of stone column on drainage capacity during soil liquefaction," Soils and Foundations, vol. 59, no. 1, pp. 196-207, 2019.

[37] G. M. Firedman and J. E. Sanders, Principles of Sedimentology, John Wiley, Hoboken, NJ, USA, 1978.

[38] H. W. Sun, "Different soil classifications in domestie geoteehnieal standards," in Proceedings of the 2nd National Conference on Engineering Safety and Protection, Beijing, China, August 2010.

[39] J. Q. Ma and S. B. Li, "Seepage control design for the looses dam foundation of zhuoyu reservoir in Tibet," Science Technology and Engineering, vol. 18, no. 10, pp. 136-143, 2018.

[40] K. Terzaghi, R. B. Peck, and G. Mesri, Soil Mechanics in Engineering Practice, A Wiley-Interscience Publication, John Wiley \& Son, Inc., Hoboken, NJ, USA, 3rd edition, 1996.

[41] P DL/T 5356-2006, Code for Coarse-Grained Soil Tests for Hydropower and Water Conservancy Engineering, National Development and Reform Commission, Beijing, China, 2006.

[42] L. N. Reddi, M. Xiao, M. G. Hajra, and I. M. Lee, "Physical clogging of soil filters under constant flow rate versus constant head," Canadian Geotechnical Journal, vol. 42, no. 3, pp. 804-811, 2005.

[43] S. L. Coustumer, T. D. Fletcher, A. Deletic, S. Barraud, and P. Poelsma, "The influence of design parameters on clogging of stormwater biofilters: a large-scale column study," Water Research, vol. 46, no. 20, pp. 6743-6752, 2012.

[44] D. C. Mays, "Contrasting clogging in granular media filters, soils, and dead-end membranes," Journal of Environmental Engineering, vol. 136, no. 5, pp. 475-480, 2010.

[45] D. M. Mintz, S. A. Schubert, Y. J. Hui, and H. M. Ma, Hydraulics on Granular Materials, Water Conservancy Press, Beijing, China, 1957.

[46] G. F. Hua, W. Zhu, L. F. Zhao, and J. Y. Huang, "Clogging pattern in vertical-flow constructed wetlands: insight from a laboratory study," Journal of Hazardous Materials, vol. 180, no. 1-3, pp. 668-674, 2010.
[47] J. Fetzer, M. Holzner, M. Plötze, and G. Furrer, "Clogging of an Alpine streambed by silt-sized particles-insights from laboratory and field experiments," Water Research, vol. 126, pp. 60-69, 2017. 